\title{
Dapagliflozin as Monotherapy or Combination Therapy in Japanese Patients with Type 2 Diabetes: an Open-Label Study
}

\author{
Kohei Kaku $\cdot$ Hiroshi Maegawa $\cdot$ Yukio Tanizawa $\cdot$ Arihiro Kiyosue • \\ Yumiko Ide $\cdot$ Takuto Tokudome $\cdot$ Yuji Hoshino $\cdot$ Jisin Yang • \\ Anna Maria Langkilde
}

To view enhanced content go to www.diabetestherapy-open.com

Received: August 5, 2014 / Published online: October 24, 2014

(C) The Author(s) 2014. This article is published with open access at Springerlink.com

\section{ABSTRACT}

Introduction: Dapagliflozin is a selective sodium glucose co-transporter 2 inhibitor that improves glycemic control and reduces body weight and systolic blood pressure in patients with type 2 diabetes mellitus (T2DM). Dapagliflozin is effective and well tolerated over 12-24 weeks in Japanese patients with T2DM. In this study, the safety and efficacy of dapagliflozin administered as monotherapy and

Trial Registration: ClinicalTrials.gov \#NCT01294436.

Electronic supplementary material The online version of this article (doi:10.1007/s13300-014-0086-7) contains supplementary material, which is available to authorized users.

K. Kaku $(\bowtie)$

Department of Internal Medicine, Kawasaki Medical

School, Okayama, Japan

e-mail: kka@med.kawasaki-m.ac.jp

H. Maegawa

Shiga University of Medical Sciences, Otsu-City,

Shiga, Japan

Y. Tanizawa

Yamaguchi University School of Medicine,

Yamaguchi, Japan

A. Kiyosue

Tokyo Eki Center-Building Clinic, Tokyo, Japan combination therapy were assessed over 52 weeks in Japanese patients with T2DM.

Methods: This was a 52-week open-label Phase 3 study consisting of a single treatment arm with no comparator. Dapagliflozin was administered as monotherapy $(n=249)$ or combination therapy $(n=479)$ with existing antihyperglycemic agents (sulfonylurea, glinides, metformin, alpha-glucosidase inhibitors, thiazolidinediones, dipeptidyl peptidase-4 inhibitors, or glucagon-like peptide-1 receptor agonists) to Japanese patients with T2DM and inadequate glycemic control for 52 weeks. Treatment with dapagliflozin was initiated at $5 \mathrm{mg} /$ day and titrated to $10 \mathrm{mg} /$ day as required.

Y. Ide

Tokyo Center Clinic, Tokyo, Japan

T. Tokudome

Bristol-Myers K.K, Tokyo, Japan

Y. Hoshino $\cdot$ J. Yang

AstraZeneca K.K, Osaka, Japan

A. M. Langkilde

AstraZeneca R\&D, Mölndal, Sweden 
Results: Dapagliflozin administered as monotherapy or combination therapy was well tolerated. The frequency of adverse events (AEs) over 52 weeks was similar between monotherapy (79.1\%) and combination therapy (72.4\%) groups, and AEs were mostly mild or moderate. The incidence of hypoglycemia at 52 weeks was $2.4 \%$ in the monotherapy group and $4.0 \%$ in the combination therapy group. In patients receiving dapagliflozin as monotherapy or combination therapy, reductions from baseline to week 52 were observed in glycosylated hemoglobin $\left(\mathrm{HbA}_{1 \mathrm{c}}\right)(-0.7 \%$ in both groups), weight ( -2.6 and $-2.1 \mathrm{~kg}$, respectively), and systolic blood pressure $(-5.2 \mathrm{mmHg}$ and $-3.9 \mathrm{mmHg}$ ). In patients with insufficient response to $5 \mathrm{mg} /$ day, dapagliflozin was increased to $10 \mathrm{mg} / \mathrm{day}$, and a further decrease in $\mathrm{HbA}_{1 \mathrm{c}}$ from the pre-titration value was observed in both groups.

Conclusion: Dapagliflozin was well tolerated and effective as monotherapy or combination therapy in Japanese patients with T2DM over 52 weeks.

Keywords: Dapagliflozin; Diabetes; Japanese patients; Selective sodium glucose cotransporter 2, SGLT2; Type 2 diabetes

\section{INTRODUCTION}

Type 2 diabetes mellitus (T2DM) is a chronic and progressive disorder associated with an increased risk of microvascular and macrovascular complications [1]. Despite the wide array of available medications, many patients do not achieve the recommended level of glycemic control [2]. Most antihyperglycemic drugs target a reduction in insulin resistance or enhance insulin secretion and, due to the progressive nature of the disease, often lose efficacy over time. Inhibitors of sodium glucose co-transporter 2 (SGLT2) are a new class of oral antihyperglycemic drugs (OADS) whose efficacy is independent of insulin sensitivity and secretion. Healthy kidneys filter $\sim 180 \mathrm{~g}$ of glucose daily [3], the majority of which is reabsorbed at the level of the proximal tubule through SGLT2 [4]. SGLT2 inhibitors improve glycemic control through a reduction in filtered glucose reabsorption and a resultant increase in urinary glucose excretion. As this class of drug is not dependent on the ability of the pancreatic $\beta$ cells to secrete insulin, they have the potential to be used throughout the course of the disease.

Dapagliflozin is an orally active, highly selective SGLT2 inhibitor that has been shown to significantly improve glycemic control. Across a global clinical development program involving analyses of Phase IIB/III trials, treatment with dapagliflozin, as monotherapy or in conjunction with preexisting OADs, was associated with reductions in glycosylated hemoglobin $\left(\mathrm{HbA}_{1 \mathrm{c}}\right)$ and fasting plasma glucose (FPG) as well as reductions or stabilization of body weight and systolic blood pressure (SBP) in patients with T2DM [5-13].

In Japanese patients with T2DM, the efficacy of dapagliflozin on glycemic parameters and body weight has been demonstrated over 12-24 weeks [14, 15]. In the 24-week trial, a greater proportion of Japanese patients with T2DM receiving dapagliflozin $10 \mathrm{mg}$ experienced adverse events (AEs) (64.8\%) compared with the placebo group (51.7\%); these were primarily AEs unrelated to treatment, such as nasopharyngitis and dental caries in patients receiving dapagliflozin $10 \mathrm{mg}$ $[14,15]$. In general, the safety and tolerability of dapagliflozin reported in Japanese patients were 
similar to those experienced by patients throughout the global dapagliflozin clinical development program.

The aim of this study was to evaluate the safety and tolerability of long-term treatment (up to 52 weeks) with dapagliflozin as monotherapy or in combination with other OADs, including sulfonylureas (SU), glinides, metformin, $\alpha$-glucosidase inhibitors (AGI), thiazolidinediones (TZD), dipeptidyl peptidase4 (DPP-4) inhibitors, and glucagon-like peptide1 (GLP-1) receptor agonists.

\section{METHODS AND MATERIALS}

\section{Study Design}

A single-treatment arm, open-label, Phase III study was carried out in 100 centers in Japan over 52 weeks (Clinicaltrials.gov identifier NCT01294436). The study comprised a 2-week screening period, a 4 -week lead-in period, a 52-week treatment period with a single active treatment without any comparator, and a 3-week follow-up period. The study design is shown in Fig. 1.

The active study treatment was given across eight subgroups, including one monotherapy and seven individual combination therapy groups (SU, glinides, metformin, AGI, TZD, DPP-4 inhibitors, and GLP-1 agonists). Patients in the monotherapy group receiving therapy at enrollment underwent a 6-week washout period before a 4-week lead-in period in an attempt to eliminate effects of any prior therapy.

All procedures were designed and performed in accordance with the ethical standards of the responsible committee on human experimentation (institutional and national) and with the Declaration of Helsinki of 1975, as revised in 2000 and 2008. These principles and standards are consistent with International Conference on Harmonization/Good Clinical Practice (GCP), the applicable regulatory requirements, and the AstraZeneca policy on bioethics. All patients provided informed consent prior to entering the study.
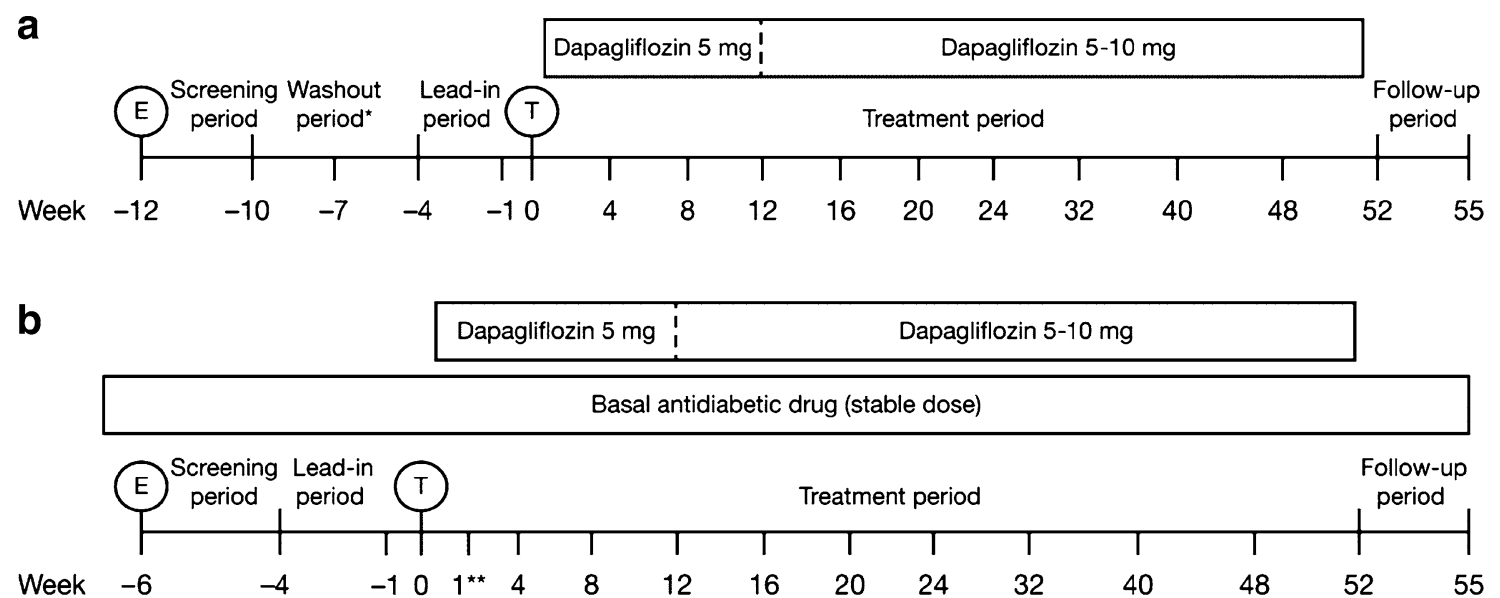

Fig. 1 Study design a monotherapy and $\mathbf{b}$ combination therapy. The asterisk indicates that the wash-out period was applicable only for subjects who received medical treatment for diabetes until enrollment. Double asterisks indicate that
Week 1 was applicable exclusively for the subgroup of combination therapy with GLP-1 agonists 


\section{Key Inclusion Criteria}

Men or women aged $\geq 20$ years with a diagnosis of T2DM were eligible for inclusion in the study. Women of childbearing potential were required to be using a highly effective method of contraception to avoid pregnancy throughout the study and for up to 4 weeks after study completion, and to have a negative urine pregnancy test within $72 \mathrm{~h}$ prior to the start of study treatment and at each visit thereafter.

\section{Monotherapy}

Patients who were given the study drug dapagliflozin as monotherapy were either previously drug naïve or were undergoing medical treatment for diabetes within 6 weeks of enrollment (single OAD or two agents with less than half of the approved maximal dose for each agent). Drug naïve was defined as either never having received medical treatment for diabetes; having received medical treatment for diabetes for $<30$ days since diagnosis and during the 30-day period prior to screening not having received $\mathrm{OAD}$ for $>3$ consecutive or $>7$ nonconsecutive days; or having previously received medical treatment for diabetes, but not having been treated within 6 weeks of enrollment.

Patients who had been treated with a TZD during the 6 months prior to enrollment were not eligible for inclusion in the monotherapy group. Patients in the monotherapy group who had a history of insulin therapy within 2 weeks of screening (except insulin therapy during a hospitalization for other causes or for gestational diabetes) were not included in any treatment arm of the study. For patients who were drug naïve, $\mathrm{HbA}_{1 \mathrm{c}}$ had to be $\geq 6.5 \%$ and $\leq 10 \%$ at enrollment (week -12), and for patients with ongoing treatment, HbA1c had to be $\leq 8 \%$ at enrollment. For all patients, $\mathrm{HbA}_{1 \mathrm{c}}$ levels had to be $\geq 6.5 \%$ and $\leq 10 \%$ at week -1 . For the monotherapy group, the proportion of patients with $\mathrm{HbA}_{1 \mathrm{c}} \geq 6.5 \%$ but $\leq 7 \%$ at week -1 needed to be, at most, $\sim 25 \%$.

\section{Combination Therapy}

For the combination therapy group, the administration of each basal OAD at stable doses was required to be within approved dose ranges (for Japan) for $\geq 8$ weeks before the start of dapagliflozin treatment, except for pioglitazone, which was required to be at stable doses and within approved dose ranges for $\geq 12$ weeks before the start of dapagliflozin treatment. Due to the mechanism of action of pioglitazone, it may take 2-3 months for pioglitazone to have full effect on glycemic control. Therefore, the required period was 12 weeks before the start of dapagliflozin treatment. $\mathrm{HbA}_{1 \mathrm{c}}$ requirements for the combination therapy group were $\geq 6.5 \%$ and $\leq 10 \%$ at enrollment and at week -1 .

\section{Key Exclusion Criteria}

Key exclusion criteria for both groups included: type 1 diabetes or diabetes insipidus; a history of ketoacidosis; FPG $>240 \mathrm{mg} / \mathrm{dL}$ ( $>3.3 \mathrm{mmol} / \mathrm{l}$ ) (at weeks -12 to -1 ); body mass index (BMI) $\geq 45.0 \mathrm{~kg} / \mathrm{m}^{2}$ at enrollment; estimated glomerular filtration rate (eGFR) $<45 \mathrm{~mL} / \mathrm{min}$ (calculated by a Japanese guideline formula [16, 17]) or a measured serum creatinine value of $>1.5 \mathrm{mg} / \mathrm{dL} \quad(>133 \mu \mathrm{mol} / \mathrm{L})$ for men and $>1.4 \mathrm{mg} / \mathrm{dL} \quad(>124 \mu \mathrm{mol} / \mathrm{L})$ for women at enrollment; severe hepatic insufficiency and/or significant abnormal liver function defined as aspartate aminotransferase $>3 \times$ upper limit of normal (ULN) and/or alanine aminotransferase $>3 \times$ ULN at enrollment; congestive heart failure defined as New York Heart Association Class IV, unstable, or acute congestive heart 
failure; or creatinine kinase $>3 \times$ ULN at enrollment.

\section{Study Procedures and Treatment}

Dapagliflozin treatment was initiated at $5 \mathrm{mg} /$ day from week 0 to week 12 along with a stable dose of basal OAD for those patients in the combination therapy subgroups. On or after week 12 , if $\mathrm{HbA}_{1 \mathrm{c}}$ was $>7.5 \%$ and there were no safety concerns, dapagliflozin was up-titrated to $10 \mathrm{mg} /$ day. After the $10 \mathrm{mg} /$ day dose of dapagliflozin was administered for 8 weeks, patients with inadequate glycemic control were considered for rescue treatment by the investigator. Down-titration to $5 \mathrm{mg}$ of dapagliflozin was not allowed after up-titration to $10 \mathrm{mg} /$ day of dapagliflozin; if the investigator determined down-titration to $5 \mathrm{mg} /$ day of dapagliflozin was necessary, the patient was withdrawn from the study.

In the combination therapy subgroups, dose reduction of the basal OAD (except for SU) was not allowed during the treatment period for any condition. If dose reduction of the basal OAD (except for SU) was needed, the patient was withdrawn from the study. A reduction of the SU dose was required if two or more readings of plasma glucose $\leq 70 \mathrm{mg} / \mathrm{dL}(\leq 3.9 \mathrm{mmol} / \mathrm{L})$ were recorded at any visit after week 0 .

\section{Rescue Criteria}

Following up-titration to $10 \mathrm{mg} /$ day dapagliflozin for $\geq 8$ weeks, if $\mathrm{HbA}_{1 \mathrm{c}}$ was still $>8 \%$ in patients from week 24 to week 52, rescue treatment was administered at the investigators' discretion. In the monotherapy subgroup, only one additional OAD could be added and gradually increased up to the approved maximum dose. In the combination therapy group, doses of the basal OAD were gradually increased up to the approved maximum doses and then, if necessary, only one additional OAD was added and gradually increased up to the approved maximum dose at the discretion of investigators following local regulation and treatment guidelines in Japan [18].

\section{Outcome Measures}

The primary endpoints were safety and tolerability, including AEs, laboratory parameters, electrocardiogram, vital signs, hypoglycemic events, eGFR (calculated using the Japanese guideline recommended equation $[16,17])$, and physical examination. Safety data were evaluated during the 52-week treatment period as well as during the 3-week safety follow-up period.

Secondary endpoints were: change in $\mathrm{HbA}_{1 \mathrm{c}}$ $\left(\mathrm{HbA}_{1 \mathrm{c}}\right.$ is measured as National Glycohemoglobin Standardization Program [NGSP]) from baseline over time during treatment period until week 52; change in $\mathrm{HbA}_{1 \mathrm{c}}$ from last pre-titration until week 8, week 16, and week 24 after up-titration; change in FPG from baseline over time during treatment period until week 52; change in FPG from last pre-titration until week 8 , week 16 , and week 24 after up-titration; change in body weight from baseline over time during treatment period until week 52; change in body weight from last pre-titration until week 8 , week 16, and week 24 after up-titration; proportion of patients achieving total body weight reduction from a baseline of $\geq 5 \%$ at week 24 and week 52; proportion of patients not rescued and achieving glycemic response defined as $\mathrm{HbA}_{1 \mathrm{c}}<7 \%$ at week 24 (last observation carried forward [LOCF]) and week 52 in patients who had $\mathrm{HbA}_{1 \mathrm{c}} \geq 7 \%$ at baseline; change in seated SBP and seated diastolic blood pressure (DBP) from baseline over time (observed) during treatment period until week 52; proportion of patients who had a seated SBP 
of $\geq 130 \mathrm{mmHg}$ at baseline with a seated SBP of $<130 \mathrm{mmHg}$ at week 24 and week 52; change in fasting insulin and fasting C-peptide from baseline over time (observed) during treatment period until week 52; and change in total cholesterol, low-density lipoprotein (LDL) cholesterol, high-density lipoprotein (HDL) cholesterol, triglycerides, and free fatty acid levels from baseline over time (observed) during treatment period until week 52. All efficacy evaluations at a specific week were made according to the LOCF principle.

The safety analysis set included all patients who received at least one dose of randomized study medication and who provided any safety records. The full analysis set included all randomized patients who received at least one dose of study medication and had baseline values and at least one post baseline value for at least one efficacy variable. Descriptive statistics are only presented and all analyses were performed with Statistical Analysis System $\left(\mathrm{SAS}^{\circledR}\right.$; SAS Institute, Cary, NC, USA) version 8.2 or higher.

\section{RESULTS}

Patient disposition is shown in Fig. 2. In brief, 728 patients were enrolled: 249 received dapagliflozin as monotherapy and 479 received dapagliflozin in combination with other OADs $(89 \%$ and $85 \%$ completed the 52-week monotherapy and combination therapy treatment periods, respectively). The demographics and baseline characteristics were generally balanced across the groups. However, the duration of T2DM was longer in the combination group (Table 1).

At baseline, of the 479 patients in the combination group 122 (25.5\%) were taking SUs (glimepiride), 62 (12.9\%) DPP-4 inhibitors (sitagliptin), $61 \quad(12.7 \%)$ AGIs (acarbose, miglitol, and voglibose), 71 (14.8\%) metformin, 64 (13.4\%) TZDs (pioglitazone), 49 (10.2\%) glinides (mitiglinide and nateglinide), and 50 (10.4\%) GLP-1 analogs (liraglutide) (Table 1).

\section{Safety}

The frequency of AEs observed over the 52-week treatment period with dapagliflozin was $79.1 \%$ for the monotherapy group and $72.4 \%$ for the combination groups (Table 2) (the range across the combination groups was 63.9-78.9\%). AEs were mostly mild or moderate in intensity, and the frequency of serious AEs was $5.6 \%$ in the monotherapy group and $3.1 \%$ for the

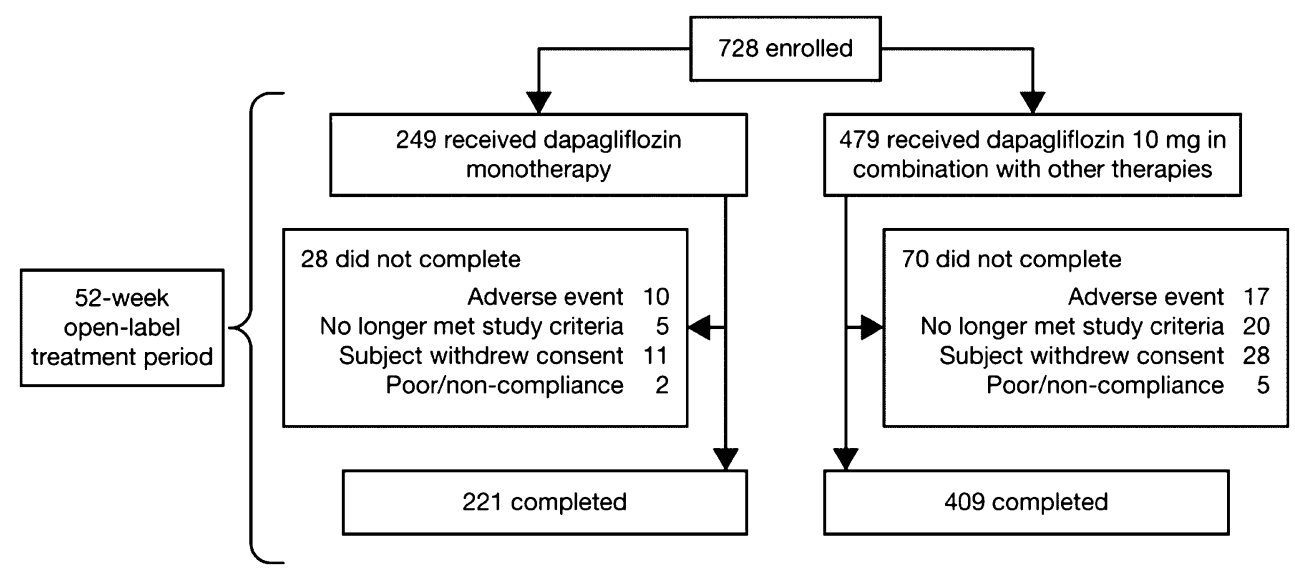

Fig. 2 Patient disposition 
Table 1 Demographics and baseline characteristics

\begin{tabular}{|c|c|c|}
\hline & $\begin{array}{l}\text { Monotherapy } \\
(n=249)\end{array}$ & $\begin{array}{l}\text { All combination } \\
\text { therapies }(n=479)\end{array}$ \\
\hline Age, years, mean $(\mathrm{SD})$ & $58.1(10.4)$ & $57.2(10.1)$ \\
\hline Sex, male, $n(\%)$ & $146(58.6)$ & $268(55.9)$ \\
\hline Seated SBP, mmHg, mean (SD) & $127.5(13.7)$ & $125.8(14.1)$ \\
\hline Seated DBP, mmHg, mean (SD) & $79.1(9.5)$ & $76.2(9.8)$ \\
\hline Weight, kg, mean (SD) & $67.8(13.4)$ & $67.4(14.5)$ \\
\hline $\mathrm{BMI}, \mathrm{mg} / \mathrm{m}^{2}$, mean $(\mathrm{SD})$ & $25.7(4.2)$ & $25.6(4.4)$ \\
\hline Waist circumference, $\mathrm{cm}$, mean (SD) & $88.3(10.7)$ & $88.3(11.1)$ \\
\hline Duration of T2DM, years, mean (SD) & $3.8(4.0)$ & $6.9(6.1)$ \\
\hline $\mathrm{HbA}_{1 \mathrm{c}}, \%$, mean $(\mathrm{SD})$ & $7.5(0.8)$ & $7.8(0.9)$ \\
\hline $\mathrm{FPG}, \mathrm{mg} / \mathrm{dL}[\mathrm{mmol} / \mathrm{L}]$, mean $(\mathrm{SD})$ & $140.3(25.4)[7.8(1.4)]$ & $147.4(29.1)[8.2(1.6)]$ \\
\hline $\mathrm{eGFR}\left(\mathrm{mL} / \mathrm{min} / 1.73 \mathrm{~m}^{2}\right)$, mean $(\mathrm{SD})$ & $68.6(12.2)$ & $70.5(13.5)$ \\
\hline $\mathrm{eGFR}<45 \mathrm{~mL} / \mathrm{min} / 1.73 \mathrm{~m}^{2}, n(\%)$ & $0(0)$ & $0(0)$ \\
\hline $\mathrm{eGFR} \geq 45-60 \mathrm{~mL} / \mathrm{min} / 1.73 \mathrm{~m}^{2}, n(\%)$ & $61(24.5)$ & $97(20.3)$ \\
\hline $\mathrm{eGFR} \geq 60-90 \mathrm{~mL} / \mathrm{min} / 1.73 \mathrm{~m}^{2}, n(\%)$ & $175(70.3)$ & $347(72.4)$ \\
\hline $\mathrm{eGFR} \geq 90 \mathrm{~mL} / \mathrm{min} / 1.73 \mathrm{~m}^{2}, n(\%)$ & $13(5.2)$ & $35(7.3)$ \\
\hline \multicolumn{3}{|l|}{ Baseline use of antidiabetic medications $n(\%)$} \\
\hline \multicolumn{3}{|l|}{ Sulfonylurea $(n=122,25.5 \%)$} \\
\hline \multicolumn{3}{|l|}{ Glimepiride } \\
\hline $0.5 \mathrm{mg}, n(\%)$ & - & $2 / 122(1.6)$ \\
\hline $1 \mathrm{mg}, n(\%)$ & - & $67 / 122(54.9)$ \\
\hline $1.5 \mathrm{mg}, n(\%)$ & - & $3 / 122(2.5)$ \\
\hline $2 \mathrm{mg}, n(\%)$ & - & $23 / 122(18.9)$ \\
\hline $2.5 \mathrm{mg}, n(\%)$ & - & $1 / 122(0.8)$ \\
\hline $3 \mathrm{mg}, n(\%)$ & - & $14 / 122(11.5)$ \\
\hline $4 \mathrm{mg}, n(\%)$ & - & $5 / 122(4.1)$ \\
\hline $5 \mathrm{mg}, n(\%)$ & - & $1 / 122(0.8)$ \\
\hline $6 \mathrm{mg}, n(\%)$ & - & $6 / 122(4.9)$ \\
\hline \multicolumn{3}{|c|}{ Dipeptidyl peptidase- 4 inhibitors $(n=62,12.9 \%)$} \\
\hline \multicolumn{3}{|l|}{ Sitagliptin } \\
\hline $25 \mathrm{mg}, n(\%)$ & - & $2 / 62(3.2)$ \\
\hline $50 \mathrm{mg}, n(\%)$ & - & $46 / 62(74.2)$ \\
\hline $100 \mathrm{mg}, n(\%)$ & - & $14 / 62(22.6)$ \\
\hline
\end{tabular}


Table 1 continued

\section{Monotherapy}

$(n=249)$
All combination

therapies $(n=479)$

$\alpha$-glucosidase inhibitors $(n=61,12.7 \%)$

Acarbose

$150 \mathrm{mg}, n(\%)$

$300 \mathrm{mg}, n(\%)$

$-$

$1 / 61(1.6)$

Miglitol

$150 \mathrm{mg}, n(\%)$

$225 \mathrm{mg}, n(\%)$

$-$

23/61 (37.7)

Voglibose

$0.6 \mathrm{mg}, n(\%)$

$-$

$16 / 61(26.2)$

$0.9 \mathrm{mg}, n(\%)$

$16 / 61(26.2)$

Metformin $(n=71,14.8 \%)$

$500 \mathrm{mg}$

$-$

18/71 (25.4)

$750 \mathrm{mg}$

$-$

38/71 (53.5)

$1,000 \mathrm{mg}$

$-$

$3 / 71(4.2)$

$1,500 \mathrm{mg}$

-

$12 / 71(16.9)$

Thiazolidinediones $(n=64,13.4 \%)$

Pioglitazone

$15 \mathrm{mg}$

$-$

$32 / 64(50.0)$

$30 \mathrm{mg}$

$-$

$31 / 64(48.4)$

$45 \mathrm{mg}$

-

$1 / 64(1.6)$

Glinide $(n=49,10.2 \%)$

Mitiglinide

$30 \mathrm{mg}$

-

$22 / 49(44.9)$

Nateglinide

$270 \mathrm{mg}$

Glucagon-like peptide-1 analogs $(n=50,10.4 \%)$

Liraglutide

$0.6 \mathrm{mg}$

- $\quad 7 / 50(14.0)$

$0.9 \mathrm{mg}$

$-$

$43 / 50(86.0)$

$B M I$ body mass index, $D P B$ diastolic blood pressure, $e G F R$ estimated glomerular filtration rate, FPG fasting plasma glucose, $H b A_{1 c}$ glycosylated hemoglobin, $S B P$ systolic blood pressure, $S D$ standard deviation, T2DM type 2 diabetes mellitus 
Table 2 Safety and tolerability over 52 weeks

\begin{tabular}{lll}
\hline & $\begin{array}{l}\text { Monotherapy } \\
(\boldsymbol{n}=\mathbf{2 4 9 )}\end{array}$ & $\begin{array}{l}\text { All combination } \\
\text { therapies }(\boldsymbol{n}=\mathbf{4 7 9})\end{array}$ \\
\hline At least 1 AE, $n$ (\%) & $197(79.1)$ & $347(72.4)$ \\
At least 1 serious AE, $n$ (\%) & $14(5.6)$ & $15(3.1)$ \\
At least 1 episode of hypoglycemia, $n(\%)$ & $6(2.4)$ & $19(4.0)$ \\
Deaths, $n$ & 0 & 0 \\
Events of urinary tract infection, $n(\%)^{\mathrm{a}}$ & $9(3.6)$ & $11(2.3)$ \\
Events of genital infection, $n(\%)^{\mathrm{a}}$ & $7(2.8)$ & $12(2.5)$ \\
Fractures, $n$ (\%) & $6(2.4)$ & $6(1.3)$ \\
Malignant and unspecified neoplasms, $n(\%)$ & $5(2.0)$ & $2(0.4)$ \\
Mean change in eGFR mL/min/1.73 m ${ }^{2}(\mathrm{SE})$ & $0.2(0.6)$ & $0.1(0.5)$ \\
Renal impairment, $n(\%)$ & $5(2.0)$ & $16(3.3)$ \\
Volume-related events, $n(\%)$ & $3(1.2)$ & $2(0.4)$ \\
Most common AEs $(\geq 4 \%), n(\%)$ & & $116(24.2)$ \\
Nasopharyngitis & $63(25.3)$ & $13(2.7)$ \\
Pollakiuria & $13(5.2)$ & $10(2.1)$ \\
Upper respiratory tract infection & $12(4.8)$ & $22(4.6)$ \\
Constipation & $9(3.6)$ & $12(2.5)$ \\
Eczema & $11(4.4)$ & $21(4.4)$ \\
Back pain & $10(4.0)$ & $8(1.7)$ \\
Thirst & $10(4.0)$ & $11(2.3)$ \\
Dental caries & $10(4.0)$ & \\
\hline & &
\end{tabular}

$A E$ adverse event, $e G F R$ estimated glomerular filtration rate, $S E$ standard error

${ }^{a}$ Based on a predefined list of events

combination group (range 1.6-4.8\%). reported was nasopharyngitis, which was Hypoglycemic events were experienced by experienced by approximately a quarter of fewer patients in the monotherapy group vs. the combination therapy group $(2.4 \%$ and $4.0 \%$, respectively). In the combination therapy subgroups, the frequency of hypoglycemic events was highest in patients receiving SU, glinides, and GLP-1 agonists (6.6, 6.1 , and $6.0 \%$, respectively). There were no major hypoglycemic events, and no patient was discontinued from the study due to a hypoglycemic event. The most common $\mathrm{AE}$ patients in both groups (63 [25.3\%] and 116 [24.2\%] in monotherapy and combination groups, respectively). Events of urinary tract infection were rare, and rates were similar in the monotherapy and combination therapy groups (3.6\% and $2.3 \%$, respectively). Similarly, events of genital infection were rare, and the rates were balanced between monotherapy and combination therapy groups $(2.8 \%$ and $2.5 \%$, respectively). Rates of renal impairment, 
fractures, and volume-related events were low and similar in the monotherapy and combination therapy groups (Table 2).

eGFR values declined from week 0 to week 8 in both monotherapy and combination therapy groups (change from baseline, -2.9 and $-2.5 \mathrm{~mL} / \mathrm{min} / 1.73 \mathrm{~m}^{2}$, respectively) and by week 24 had returned to close to baseline values (change from baseline, 0.5 and $0.1 \mathrm{~mL}$ / $\min / 1.73 \mathrm{~m}^{2}$, respectively).

There was no clinically meaningful change in mean values of serum creatinine in either therapy group during the 52-week, open-label treatment period.

Seven of the 728 patients (1\%) reported neoplasms (benign, malignant, or unspecified) over the 52-week study period (5 in the monotherapy group and 2 in the combination group). There were two cases of colon cancer (day 55 and day 242) and one each of breast cancer (day 149), rectal cancer (day 70), gastric neoplasm (day 281), metastatic neoplasm (day 321), and squamous cell carcinoma (day 188).

The effects of dapagliflozin on clinical laboratory data are shown in Table 3. Following 52 weeks of treatment with dapagliflozin, urinary glucose increased from baseline in both groups (monotherapy group 2,545.40 mg/dL [141.27 mmol/L]; combination therapy group $2,839.50 \mathrm{mg} / \mathrm{dL}$ [157.59 mmol/ L]). In both the monotherapy and the combination therapy groups, reductions from baseline were observed in serum uric acid $(-0.61 \mathrm{mg} / \mathrm{dL}[-36.29 \mu \mathrm{mol} / \mathrm{L}]$ and $-0.50 \mathrm{mg} /$ $\mathrm{dL} \quad[-29.74 \mu \mathrm{mol} / \mathrm{L}]$, respectively) and urine albumin $\quad(-22.40 \mathrm{mg} / \mathrm{L}$ and $-25.00 \mathrm{mg} / \mathrm{L})$. Reductions in urine sodium were observed in both the monotherapy and the combination

Table 3 Change in laboratory parameters from baseline to week 52

\begin{tabular}{|c|c|c|}
\hline & $\begin{array}{l}\text { Monotherapy } \\
(n=249) \\
\text { Mean (SE) }\end{array}$ & $\begin{array}{l}\text { All combination therapies } \\
(n=479) \\
\text { Mean (SE) }\end{array}$ \\
\hline Albumin, $\mathrm{g} / \mathrm{dL}[\mathrm{g} / \mathrm{L}]$ & $0.02(0.01)[0.20(0.14)]$ & $0.01(0.01)[0.10(0.09)]$ \\
\hline Cystatin C, mg/L $[\mathrm{nmol} / \mathrm{L}]$ & $-0.01(0.01)[-1.05(0.41)]$ & $-0.01(0.00)[-0.97(0.28)]$ \\
\hline Hematocrit, \% & $2.17(0.14)$ & $2.00(0.11)$ \\
\hline Inorganic phosphorous, $\mathrm{mg} / \mathrm{dL}[\mathrm{mmol} / \mathrm{L}]$ & $-0.01(0.03)[0.00(0.01)]$ & $0.01(0.02)[0.00(0.01)]$ \\
\hline Magnesium, $\mathrm{mEq} / \mathrm{L}[\mathrm{mmol} / \mathrm{L}]$ & $0.05(0.01)[0.03(0.00)]$ & $0.05(0.01)[0.03(0.00)]$ \\
\hline Parathyroid hormone, $\mathrm{pg} / \mathrm{mL}[\mathrm{ng} / \mathrm{L}]$ & $0.80(1.22)[0.80(1.22)]$ & $5.00(0.94)[5.00(0.94)]$ \\
\hline Serum calcium, mg/dL $[\mathrm{mmol} / \mathrm{L}]$ & $-0.02(0.02)[-0.01(0.01)]$ & $-0.06(0.02)[-0.02(0.00)]$ \\
\hline Serum creatinine, $\mathrm{mg} / \mathrm{dL}[\mu \mathrm{mol} / \mathrm{L}]$ & $0.00(0.01)[0.00(0.47)]$ & $-0.01(0.00)[-0.53(0.35)]$ \\
\hline Serum potassium, $\mathrm{mEq} / \mathrm{L}$ & $-0.03(0.02)[-0.03(0.02)]$ & $-0.03(0.02)[-0.03(0.02)]$ \\
\hline Serum sodium, $\mathrm{mEq} / \mathrm{L}[\mathrm{mmol} / \mathrm{L}]$ & $0.30(0.16)[0.30(0.16)]$ & $0.10(0.12)[0.10(0.12)]$ \\
\hline Serum uric acid, $\mathrm{mg} / \mathrm{dL}[\mu \mathrm{mol} / \mathrm{L}]$ & $-0.61(0.06)[-36.29(3.44)]$ & $-0.50(0.04)[-29.74(2.22)]$ \\
\hline Total protein, g/dL $[\mathrm{g} / \mathrm{L}]$ & $0.04(0.02)[0.40(0.24)]$ & $0.03(0.02)[0.30(0.17)]$ \\
\hline Urine glucose, $\mathrm{mg} / \mathrm{dL}[\mathrm{mmol} / \mathrm{L}]$ & $2,545.40(122.98)[141.27(6.83)]$ & $2,839.50(93.90)[157.59(5.21)]$ \\
\hline Urine albumin, $\mathrm{mg} / \mathrm{L}$ & $-22.40(9.45)$ & $-25.00(5.56)$ \\
\hline Urine sodium, $\mathrm{mEq} / \mathrm{L}[\mathrm{mmol} / \mathrm{L}]$ & $-2.40(3.46)[-2.40(3.46)]$ & $-11.10(2.60)[-11.10(2.60)]$ \\
\hline
\end{tabular}


therapy groups $(-2.40 \mathrm{mEq} / \mathrm{L}[-2.40 \mathrm{mmol} / \mathrm{L}]$ and $\quad-11.10 \mathrm{mEq} / \mathrm{L} \quad[-11.10 \mathrm{mmol} / \mathrm{L}]$, respectively) and increases were seen in parathyroid hormone $(0.80 \mathrm{pg} / \mathrm{ml}[0.80 \mathrm{ng} / \mathrm{L}]$ and $5.00 \mathrm{pg} / \mathrm{mL}[5.00 \mathrm{ng} / \mathrm{L}])$. No meaningful changes from baseline in serum sodium and or potassium were observed in either the monotherapy $(0.30 \mathrm{mEq} / \mathrm{L}[0.30 \mathrm{mmol} / \mathrm{L}]$ and $-0.03 \mathrm{mEq} / \mathrm{L} \quad[-0.03 \mathrm{mmol} / \mathrm{L}]$, respectively) or combination therapy $(0.10 \mathrm{mEq} / \mathrm{L}[0.10 \mathrm{mmol} /$ $\mathrm{L}]$ and $-0.03 \mathrm{mEq} / \mathrm{L}[-0.03 \mathrm{mmol} / \mathrm{L}])$ groups. Over 52 weeks, no change was apparent in serum calcium in either the monotherapy $(-0.02 \mathrm{mg} / \mathrm{dL}[0.00 \mathrm{mmol} / \mathrm{L}])$ or combination therapy $(-0.06 \mathrm{mg} / \mathrm{dL}[-0.02 \mathrm{mmol} / \mathrm{L}])$ group.

\section{Efficacy}

Reductions in $\mathrm{HbA}_{1 \mathrm{c}}$ levels from baseline to week 52 with dapagliflozin were the same in the monotherapy and combination therapy groups ( $-0.7 \%$ for both) (Table 4 ; Fig. 3a). No patients were rescued due to lack of glycemic control in either group. In addition, reductions in $\mathrm{HbA}_{1 \mathrm{c}}$ were similar across each of the individual combination therapies (range -0.5 to $-0.9 \%$ ) (Fig. 4). In both the monotherapy and combination therapy groups, reductions in $\mathrm{HbA}_{1 \mathrm{c}}$ from baseline to week 52 with dapagliflozin were greater in patients with higher baseline $\mathrm{HbA}_{1 \mathrm{c}}$ (Fig. 5a). Similarly, in both groups, the reductions in $\mathrm{HbA}_{1 \mathrm{c}}$ with dapagliflozin were more pronounced in patients with higher baseline kidney function (eGFR) (Fig. 5b). A greater proportion of patients achieved $\mathrm{HbA}_{1 \mathrm{c}}$ levels $<7 \%$ with dapagliflozin in the monotherapy group $(53.4 \%)$ versus the combination therapy group (35.1\%) (Table 4).

Following treatment with dapagliflozin, total body weight was reduced to a similar degree in the monotherapy and combination therapy groups (Table 4; Fig. 3b). In the monotherapy treatment group, $33.7 \%$ of patients achieved a body weight loss of $\geq 5 \%$ compared with $24.1 \%$ in the combination therapy group (Table 4).

Body mass index, waist circumference, FPG levels, fasting insulin, and fasting C-peptide were also reduced to a similar extent in the dapagliflozin monotherapy and combination therapy groups (Table 4). SBP and DBP were reduced in both the monotherapy group and the combination therapy groups. Approximately half of all patients in either group with baseline SBP $\geq 130 \mathrm{mmHg}$ achieved reductions in SBP to $<130 \mathrm{mmHg}$.

Numerical increases were observed in total, LDL, and HDL cholesterol and free fatty acid levels in both the monotherapy and combination therapy groups (Table 4). Triglyceride levels dropped in both therapy groups.

\section{Effect of Up-Titration of Dapagliflozin on Glycemic Control}

The first patients were up-titrated from dapagliflozin $5 \mathrm{mg}$ /day to $10 \mathrm{mg} /$ day at week 16. In total, $50 / 249$ patients $(20.1 \%)$ in the monotherapy group and $177 / 477$ patients (37.1\%) in the combination therapy were uptitrated to $10 \mathrm{mg} /$ day dapagliflozin.

Following dapagliflozin up-titration, there was a further mean reduction in $\mathrm{HbA}_{1 \mathrm{c}}$ in patients receiving monotherapy (last pretitration $\mathrm{HbA}_{1 \mathrm{c}}$ value 7.9 [SD 0.6]: week 8, $-0.12 \%$; week $16,-0.07 \%$; week $24,-0.12 \%$ ), as well as in patients receiving combination therapy (last pre-titration $\mathrm{HbA}_{1 \mathrm{c}}$ value 8.0 [0.6]: week $8,-0.12 \%$; week $16,-0.12 \%$; week 24 , $-0.11 \%)$.

The percentages of patients in the monotherapy and combination therapy groups with FPG of $\geq 126 \mathrm{mg} / \mathrm{dL}$ [ $\geq 7.0 \mathrm{mmol} / \mathrm{L}]$ before up-titration who achieved FPG of $<126 \mathrm{mg} / \mathrm{dL}$ $[<7.0 \mathrm{mmol} / \mathrm{L}]$ at 8 weeks after up-titration (LOCF) were $24.4 \%$ and $15.7 \%$, respectively. 
Table 4 Change in efficacy measurements from baseline to week 52

\section{Monotherapy}

$(n=249)$

$\mathrm{HbA}_{1 \mathrm{c}}, \%$

Baseline mean (SD)

Mean change from baseline (95\% CI)

Proportion of patients achieving HbAlc $<7 \%$

$n$ with $\mathrm{HbA}_{1 \mathrm{c}} \geq 7.0 \%$ at baseline

Baseline mean (SD) $\mathrm{HbA}_{1 \mathrm{c}}$ \%

Responders, \% (95\% CI)

Total body weight, $\mathrm{kg}$

Baseline mean (SD)

Mean change from baseline (95\% CI)

Proportion of patients achieving body weight reduction $\geq 5 \%$ at week 52

Baseline mean (SD) body weight, $\mathrm{kg}$

Responders, \% (95\% CI)

Mean BMI, $\mathrm{mg} / \mathrm{m}^{2 a}$

Baseline mean (SD)

Mean change from baseline (95\% CI)

Waist circumference, $\mathrm{cm}^{\mathrm{a}}$

Baseline mean (SD)

Mean change from baseline (95\% CI)

FPG, $\mathrm{mg} / \mathrm{dL}[\mathrm{mmol} / \mathrm{L}]$

Baseline mean (SD)

Mean change from baseline (95\% CI)

Mean SBP, $\mathrm{mmHg}^{\mathrm{a}}$

Baseline mean (SD)

Mean change from baseline (95\% CI)

Mean DBP, $\mathrm{mmHg}^{\mathrm{a}}$

Baseline mean (SD)

Mean change from baseline (95\% CI)

$88.1(10.8)$
$7.5(0.8)$

$-0.7(-0.8$ to -0.6$)$

189

$7.8(0.7)$

$53.4(46.1$ to 60.7$)$

$67.8(13.4)$

$-2.6(-2.9$ to -2.3$)$

$67.8(13.4)$

33.7 (27.9 to 40.0$)$

$25.7(4.2)$

$-1.0(-1.1$ to -0.9$)$

$-2.1(-2.7$ to -1.6$)$

$140.1(24.8)[7.8(1.4)]$

$-14.3(-17.0$ to -11.6$)$

$[-0.8(-0.9$ to -0.6$)]$

$127.5(13.8)$

$-5.2(-6.8$ to -3.7$)$

$79.1(9.5)$

$-2.9(-4.0$ to -1.9$)$
All combination

therapies $(n=477)$

$7.8(0.9)$

$-0.7(-0.8$ to -0.6$)$

\section{6}

$8.1(0.8)$

35.1 (30.4 to 40.0$)$

$67.4(14.5)$

$-2.1(-2.3$ to -1.8$)$

24.1 (20.3 to 28.2$)$

$25.8(4.4)$

$-0.9(-1.0$ to -0.8$)$

$88.6(11.1)$

$-2.0(-2.4$ to -1.6$)$

$147.3(29.0)$ [8.2 (1.6)]

$-17.4(-19.8$ to -15.0$)$

$[-1.0(-1.1$ to -0.8$)]$

$125.8(14.1)$

$-3.9(-5.2$ to -2.6$)$

$76.2(9.9)$

$-2.1(-2.9$ to -1.2$)$

180

$140.1(8.0)$

53.3 (45.8 to 60.8 ) 
Table 4 continued

Fasting insulin, IU/mL $[\mathrm{pmol} / \mathrm{L}]^{\mathrm{a}}$

Baseline mean (SD)

Mean change from baseline ( $95 \% \mathrm{CI}$ )

Fasting C-peptide, ng/mL $[\mathrm{nmol} / \mathrm{L}]^{\mathrm{a}}$

Baseline mean (SD)

Mean change from baseline (95\% CI)

Total cholesterol, $\mathrm{mg} / \mathrm{dL}[\mathrm{mmol} / \mathrm{L}]^{\mathrm{a}}$

Baseline mean (SD)

Mean percent change from baseline (95\% CI)

LDL, $\mathrm{mg} / \mathrm{dL}[\mathrm{mmol} / \mathrm{L}]^{\mathrm{a}}$

Baseline mean (SD)

Mean percent change from baseline (95\% CI)

$\mathrm{HDL}, \mathrm{mg} / \mathrm{dL}[\mathrm{mmol} / \mathrm{L}]^{\mathrm{a}}$

Baseline mean (SD)

Mean percent change from baseline (95\% CI)

Triglyceride, $\mathrm{mg} / \mathrm{dL}[\mathrm{mmol} / \mathrm{L}]^{\mathrm{a}}$

Baseline mean (SD)

Mean percent change from baseline (95\% CI)

Free fatty acid, $\mathrm{mg} / \mathrm{dL}[\mathrm{mmol} / \mathrm{L}]^{\mathrm{a}}$

Baseline mean (SD)

Mean percent change from baseline (95\% CI)

\section{Monotherapy}

$(n=249)$

$$
\begin{aligned}
& 7.3(6.6)[50.8(45.5)] \\
& -2.1(-2.6 \text { to }-1.6) \\
& {[-14.6(-18.1 \text { to }-11.1)]}
\end{aligned}
$$

\section{All combination}

therapies $(n=477)$

$$
\begin{aligned}
& 7.1(8.6)[49.1(59.7)] \\
& -2.0(-2.6 \text { to }-1.4) \\
& {[-13.9(-18.1 \text { to }-9.7)]}
\end{aligned}
$$

$$
\begin{array}{ll}
2.0(1.0)[0.7(0.3)] & 1.9(1.0)[0.6(0.3)] \\
-0.2(-0.3 \text { to }-0.2) & -0.1(-0.2 \text { to }-0.1) \\
{[-0.1(-0.1 \text { to }-0.1)]} & {[0.0(-0.1 \text { to } 0.0)]}
\end{array}
$$

$204.8(33.7)[5.3(0.9)]$

3.7 (2.1 to 5.4$)$

$116.2(30.9)[3.0(0.8)]$

$4.4(1.5$ to 7.3$)$

$59.9(17.1)[1.6(0.4)]$

9.7 (7.7 to 11.8$)$

150.2 (113.5) [1.7 (1.3)]

$-8.8(-13.6$ to -3.6$)$

$12.7(4.9)[0.5(0.2)]$

$6.0(-0.2$ to 12.7$)$
$197.3(35.1)$ [5.1 (0.9)]

3.5 (2.2 to 4.8$)$

$110.2(29.9)$ [2.9 (0.8)]

$3.1(1.1$ to 5.3$)$

$58.8(15.1)[1.5(0.4)]$

8.7 (7.3 to 10.2$)$

$145.7(134.6)$ [1.7 (1.5)]

$-7.6(-11.0$ to -4.0$)$

$12.2(5.0)[0.4(0.2)]$

$9.2(4.2$ to 14.6$)$

LOCF unless otherwise specified

$n$ Number of patients in the full analysis set, $B M I$ body mass index, $C I$ confidence interval, $D P B$ diastolic blood pressure, $F P G$ fasting plasma glucose, $H b A_{1 c}$ glycosylated hemoglobin, $H D L$ high-density lipoprotein, $L D L$ low-density lipoprotein, $L O C F$ last observation carried forward, $S D$ standard deviation, $S P B$ systolic blood pressure

a Observed values

b Number of patients in the full analysis set with baseline SBP $\geq 130 \mathrm{mmHg}$ and non-missing week 52 (LOCF) value

\section{DISCUSSION}

Dapagliflozin, initiated at $5 \mathrm{mg}$ once daily and titrated, as needed, to $10 \mathrm{mg}$ once daily, was well tolerated over 52 weeks by Japanese patients with T2DM as monotherapy or combination therapy with other OADs. The frequency of AEs was similar in patients 

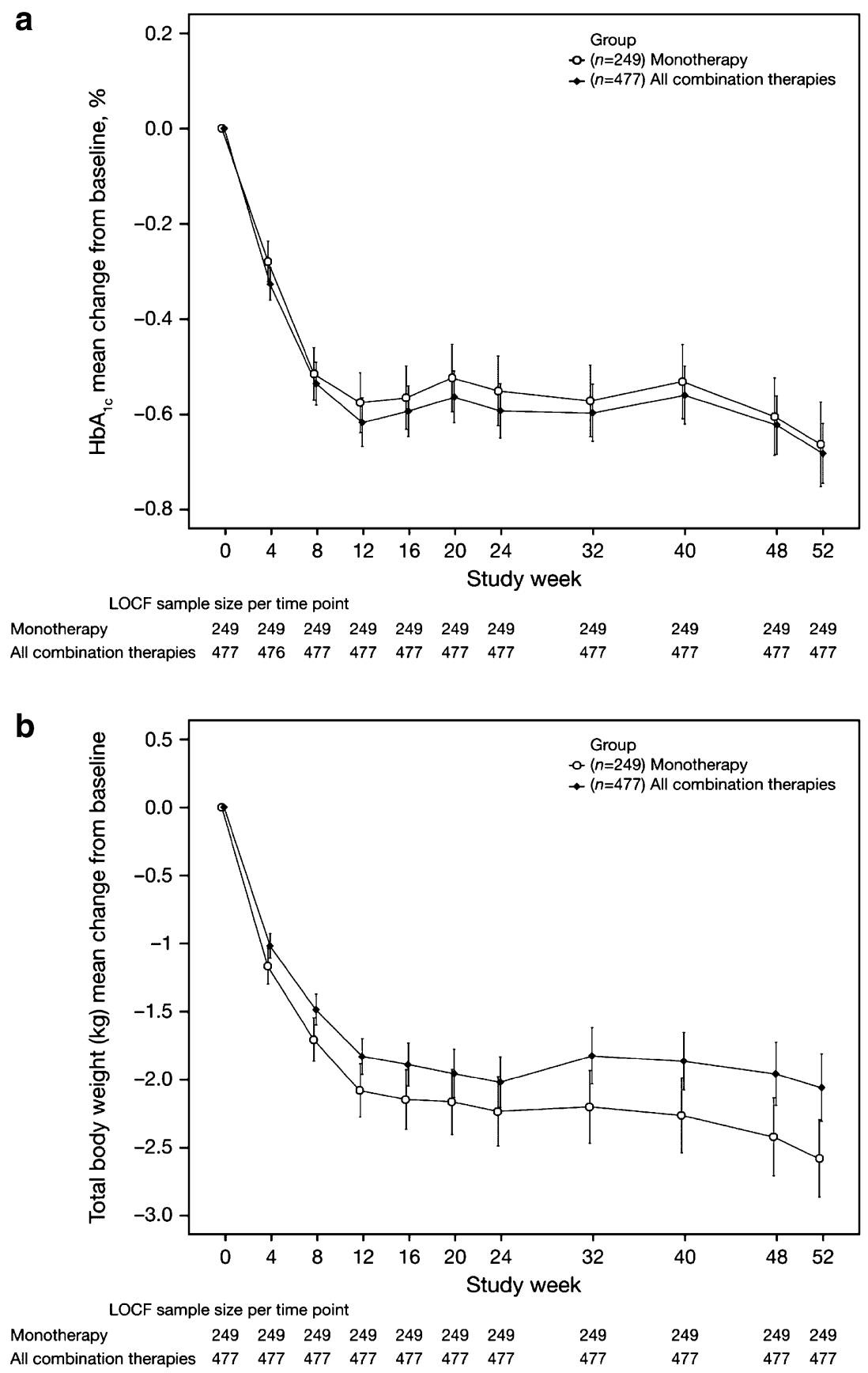

Fig. 3 Change over time with dapagliflozin (up-titrated from $5 \mathrm{mg} /$ day to $10 \mathrm{mg} /$ day) in a $\mathrm{HbA}_{\mathrm{cc}}$ and $\mathbf{b}$ total body weight. $H b A_{1 C}$ glycosylated hemoglobin, $L O C F$ last observation carried forward

receiving monotherapy or combination hypoglycemic events over 52 weeks with therapy, and AEs were mostly mild and dapagliflozin, and all were mild or moderate moderate, comprising primarily of in intensity. Fewer hypoglycemic events were nasopharyngitis, as noted in previous trials reported in patients receiving dapagliflozin $[14,15]$. There was a low incidence of monotherapy versus combination therapy, 


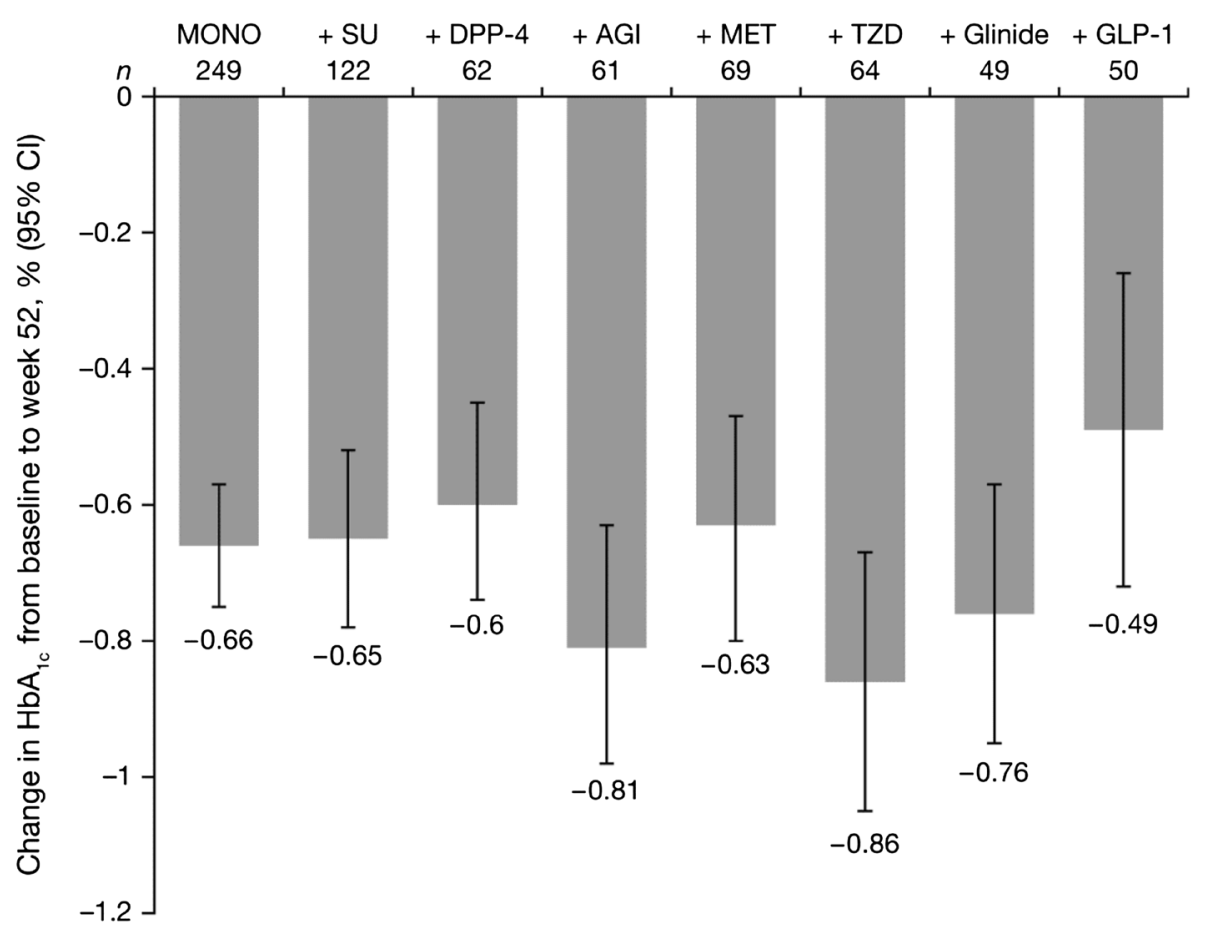

Fig. 4 Change in $\mathrm{HbA}_{1 \mathrm{c}}$ levels from baseline to week 52 by combination therapy. $A G I$-glucosidase inhibitor, $B L$ baseline, $C I$ confidence interval, DPP-4 dipeptidyl

with the highest incidence experienced by patients receiving dapagliflozin in combination with SU, glinide, and GLP-1 agonists. Urinary glucose excretion associated with the treatment of dapagliflozin in Japanese patients was comparable to that observed in a Western population $[19,20]$. Urinary tract and genital infections, often associated with SGLT2 inhibitor treatment as a consequence of the associated glucosuria [21, 22], were comparatively low $(<4 \%)$ in this study compared with pooled data from a global development program that included 12 placebo-controlled Phase IIB and III studies $(4.3 \%$ and $4.8 \%$, respectively) $[23,24]$. The effects of dapagliflozin on secondary endpoints in this study were similar to those seen in other studies. Dapagliflozin was effective in improving glycemic control as both a monotherapy and in combination with other peptidase-4, GLP-1 glucagon-like peptide-1, $H b A_{1 C}$ glycosylated hemoglobin, $M E T$ metformin, $M O N O$ monotherapy, $S U$ sulfonylurea, $T Z D$ thiazolidinedione

OADs. Consistent with previous studies, the improvement in glycemic control in this study was dependent on the baseline level of hyperglycemia [25]; a greater effect of dapagliflozin was observed in patients with higher baseline $\mathrm{HbA}_{1 \mathrm{c}}$. In addition, the improvement in glycemic control was reduced in patients with compromised renal function reflecting results observed in the Western population [26]. It should be noted that the majority of patients in this study had mild renal impairment. Patients treated with dapagliflozin maintained a mean weight loss of $2-3 \mathrm{~kg}$ over 52 weeks, and this reduction was similar between monotherapy and combination therapy groups. This likely reflects a loss of calories associated with the mechanism of action of dapagliflozin. In general, although there is some concern for sarcopenia with SGLT2 inhibitors in slim Japanese patients, the 

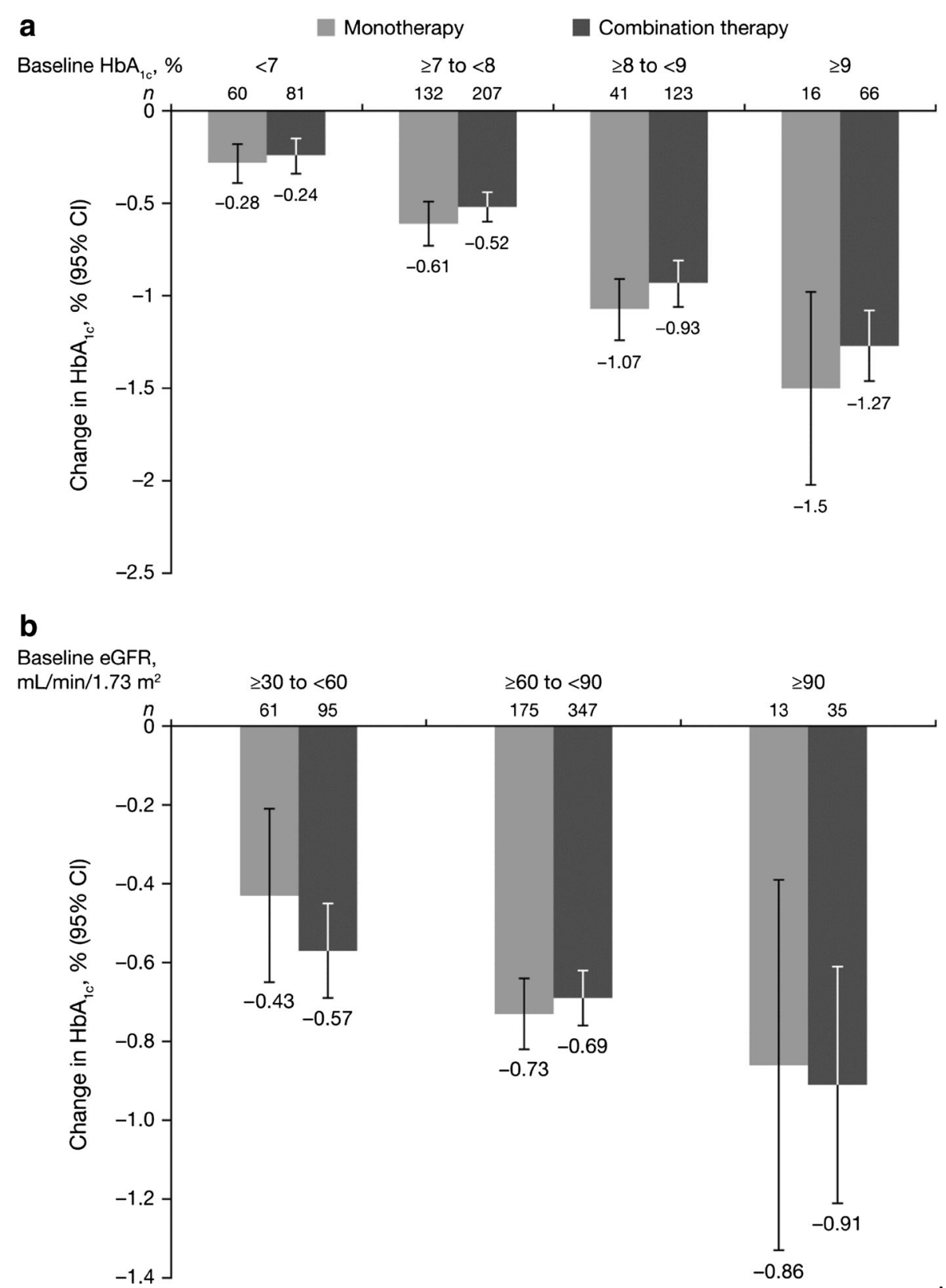

Fig. 5 Change in $\mathrm{HbA}_{1 \mathrm{c}}$ from baseline to week 52 by a $\mathrm{HbA}_{1 \mathrm{c}}$ and $\mathbf{b}$ eGFR. CI confidence interval, $e G F R$ estimated glomerular filtration rate, $H b A_{1 c}$ glycosylated hemoglobin

weight loss observed with dapagliflozin is considered to be primarily a result of a loss of fat mass [7]. A reduction in blood pressure was also observed and is presumably associated with osmotic diuresis and body weight reduction. In addition, dapagliflozin had no long-term effects on calcium, which was also observed in longer- term studies of up to 2 years [7, 26]. Overall, the results reported here over 52 weeks are consistent with those reported previously in Japanese patients and with those from the overall dapagliflozin clinical program.

The safety and efficacy of dapagliflozin were comparable in the monotherapy and 
combination therapy groups. The higher proportion of patients in the monotherapy group achieving FPG $<126 \mathrm{mg} / \mathrm{dL}[<7.0 \mathrm{mmol} /$ L] at 8 weeks after up-titration could be a consequence of the lower FPG level before uptitration in this patient cohort compared with the combination therapy group $(149.1 \mathrm{mg} / \mathrm{dL}$ [8.3 mmol/L] vs. $155.2 \mathrm{mg} / \mathrm{dL} \quad[8.6 \mathrm{mmol} / \mathrm{L}]$, respectively).

It should be taken into account when assessing the study population that this was not a randomized study, and patients with ongoing antidiabetic treatment in the combination therapy groups clearly have a different history of T2DM than those in the monotherapy group.

\section{CONCLUSION}

In conclusion, regardless of background antihyperglycemic medication, dapagliflozin was well tolerated and effective in improving glycemic control and reducing body weight in Japanese patients with inadequately controlled T2DM.

\section{ACKNOWLEDGMENTS}

The study was funded by AstraZeneca (Gaithersburg, MD, USA) and Bristol-Myers Squibb (Princeton, NJ, USA). Article processing fees were funded by AstraZeneca (Gaithersburg, MD, USA). Medical writing assistance was provided by Karen Pemberton of PPSI (a PAREXEL company, Hackensack, NJ, USA), and was funded by AstraZeneca (Gaithersburg, MD, USA). All named authors meet the ICMJE criteria for authorship for this manuscript, take responsibility for the integrity of the work as a whole, and have given final approval to the version to be published. All authors had full access to all of the data in this study and take complete responsibility for the integrity of the data and accuracy of the data analysis. Prof. Kaku is the guarantor for the study and takes full responsibility for the integrity of the work as a whole, from inception to published article.

Conflict of interest. Dr. Kaku served on speaker bureaus for Takeda, Kowa, Novo Nordisk, Novartis, MSD, and Dainippon Sumitomo; has consulted for Novo Nordisk, Takeda, Sanwa Kagaku Kenkyusho, Chugai, AstraZeneca, and Taisho; and has received research support from Takeda, Novo Nordisk, Daiichi Sankyo, Sanofi, MSD, Novartis, AstraZeneca, Chugai, and Boehringer Ingelheim. Dr. Maegawa has lectured for Sanofi, MSD, Mitsubishi Tanabe Pharma, Takeda, Eli Lilly, Sanwa Kagaku Kenkyusho, Astellas Pharma, Boehringer Ingelheim, Novartis, and AstraZeneca; conducted collaborative research with Novo Nordisk; and received research grants from Takeda, Boehringer Ingelheim, MSD, Astellas Pharma, Daiichi Sankyo, Sunstar, Teijin Pharma, Novartis, Kyowa Hakko Kirin, Dainippon Sumitomo Pharma, Mitsubishi Tanabe Pharma, AstraZeneca, and Taisho Toyama Pharmaceutical. Dr. Tanizawa has received honoraria for lectures from AstraZeneca, Novartis Pharma K.K., Takeda Pharmaceutical Company Ltd., MSD K.K., Ono Pharmaceutical Co. Ltd., Sanofi K.K., Mitsubishi Tanabe Pharma Corporation, Novo Nordisk Pharma Ltd., Nippon Boehringer Ingelheim Co. Ltd., and Dainippon Sumitomo Pharma Co. Ltd.; and scholarship funds from AstraZeneca, Kowa Pharmaceutical Co. Ltd., Dainippon Sumitomo Pharma Co., Takeda Pharmaceutical Company Ltd., MSD K.K., Astellas Pharma Inc., Daiichi Sankyo, Kyowa Hakko Kirin Co. Ltd., Sanofi 
K.K., Novartis Pharma K.K., and Nippon Boehringer Ingelheim Co. Ltd. Dr. Kiyosue and Dr. Ide declare no conflicts of interest. Dr. Tokudome is an employee and shareholder of Bristol-Myers Squibb. Dr. Hoshino and Dr. Yang are employees of AstraZeneca. Dr. Langkilde is an employee and shareholder of AstraZeneca.

Compliance with ethics guidelines. This study was designed and performed in accordance with the ethical principles that have their origin in the Declaration of Helsinki, as revised in 2000 and 2008, that are consistent with International Conference on Harmonization/Good Clinical Practice (GCP), the applicable regulatory requirements, and the AstraZeneca policy on bioethics. All patients provided informed consent prior to entering the study.

Open Access. This article is distributed under the terms of the Creative Commons Attribution Noncommercial License which permits any noncommercial use, distribution, and reproduction in any medium, provided the original author(s) and the source are credited.

\section{REFERENCES}

1. Turner R, Cull C, Holman R. United Kingdom Prospective Diabetes Study 17: a 9-year update of a randomized, controlled trial on the effect of improved metabolic control on complications in non-insulin-dependent diabetes mellitus. Ann Intern Med. 1996;124:136-45.

2. Karter AJ, Moffet HH, Liu J, et al. Achieving good glycemic control: initiation of new antihyperglycemic therapies in patients with type 2 diabetes from the Kaiser Permanente Northern California Diabetes Registry. Am J Manag Care. 2005;11:262-70.

3. Wright EM, Hirayama BA, Loo DF. Active sugar transport in health and disease. J Intern Med. 2007;261:32-43.
4. Chao EC, Henry RR. SGLT2 inhibition-a novel strategy for diabetes treatment. Nat Rev Drug Discov. 2010;9:551-9.

5. Bailey CJ, Gross JL, Pieters A, Bastien A, List JF. Effect of dapagliflozin in patients with type 2 diabetes who have inadequate glycaemic control with metformin: a randomised, double-blind, placebo-controlled trial. Lancet. 2010;375:2223-33.

6. Bolinder J, Ljunggren O, Kullberg J, et al. Effects of dapagliflozin on body weight, total fat mass, and regional adipose tissue distribution in patients with type 2 diabetes mellitus with inadequate glycemic control on metformin. J Clin Endocrinol Metab. 2012;97:1020-31.

7. Bolinder $\mathrm{J}$, Ljunggren $\mathrm{O}$, Johansson $\mathrm{L}$, et al. Dapagliflozin maintains glycaemic control while reducing weight and body fat mass over 2 years in patients with type 2 diabetes mellitus inadequately controlled on metformin. Diabetes Obes Metab. 2014;16:159-69.

8. Ferrannini E, Ramos SJ, Salsali A, Tang W, List JF. Dapagliflozin monotherapy in type 2 diabetic patients with inadequate glycemic control by diet and exercise: a randomized, double-blind, placebocontrolled, phase 3 trial. Diabetes Care. 2010;33:2217-24.

9. List JF, Woo V, Morales E, Tang W, Fiedorek FT. Sodium-glucose cotransport inhibition with dapagliflozin in type 2 diabetes. Diabetes Care. 2009;32:650-7.

10. Strojek K, Yoon KH, Hruba V, Elze M, Langkilde AM, Parikh S. Effect of dapagliflozin in patients with type 2 diabetes who have inadequate glycaemic control with glimepiride: a randomized, 24-week, double-blind, placebo-controlled trial. Diabetes Obes Metab. 2011;13:928-38.

11. Wilding JP, Norwood P, T'joen C, Bastien A, List JF, Fiedorek FT. A study of dapagliflozin in patients with type 2 diabetes receiving high doses of insulin plus insulin sensitizers: applicability of a novel insulin-independent treatment. Diabetes Care. 2009;32:1656-62.

12. Wilding JP, Woo V, Soler NG, Dapagliflozin 006 Study Group, et al. Long-term efficacy of dapagliflozin in patients with type 2 diabetes mellitus receiving high doses of insulin: a randomized trial. Ann Intern Med. 2012;156:405-15.

13. Wilding JP, Woo V, Rohwedder K, Sugg J, Parikh S, Dapagliflozin 006 Study Group. Dapagliflozin in patients with type 2 diabetes receiving high doses of insulin: efficacy and safety over 2 years. Diabetes Obes Metab. 2014;16:124-36. 
14. Kaku K, Inoue S, Matsuoka O, et al. Efficacy and safety of dapagliflozin as a monotherapy for type 2 diabetes mellitus in Japanese patients with inadequate glycaemic control: a phase II multicentre, randomized, double-blind, placebo-controlled trial. Diabetes Obes Metab. 2013;15:432-40.

15. Kaku K, Kiyosue A, Inoue S, et al. Efficacy and safety of dapagliflozin monotherapy in Japanese patients with type 2 diabetes inadequately controlled with diet and exercise. Diabetes Obes Metab. 2014;16:1102-10.

16. Japan Nephrology Society. Special issue: clinical practice guidebook for diagnosis and treatment of chronic kidney disease 2012. Nihon Jinzo Gakkai Shi. 2012;54:1034-191.

17. Matsuo S, Imai E, Horio $\mathrm{M}$, et al. Collaborators developing the Japanese equation for estimated GFR. Revised equations for estimated GFR from serum creatinine in Japan. Am J Kidney Dis. 2009;53:982-92.

18. Matsushima M. Japan Diabetes Society clinical practice guidelines. Nihon Rinsho. 2002;60:161-6.

19. Kasichayanula S, Chang M, Hasegawa M, et al. Pharmacokinetics and pharmacodynamics of dapagliflozin, a novel selective inhibitor of sodium-glucose co-transporter type 2, in Japanese subjects without and with type 2 diabetes mellitus. Diabetes Obes Metab. 2011;13:357-65.

20. Komoroski B, Vachharajani N, Feng Y, Li L, Kornhauser D, Pfister M. Dapagliflozin, a novel, selective SGLT2 inhibitor, improved glycemic control over 2 weeks in patients with type 2 diabetes mellitus. Clin Pharmacol Ther. 2009;85:513-9.

21. Clar C, Gill JA, Court R, Waugh N. Systematic review of SGLT2 receptor inhibitors in dual or triple therapy in type 2 diabetes. BMJ Open. 2012;2:e001007.

22. Geerlings S, Fonseca V, Castro-Diaz D, List J, Parikh S. Genital and urinary tract infections in diabetes: impact of pharmacologically-induced glucosuria. Diabetes Res Clin Pract. 2014;103:373-81.

23. Johnsson KM, Ptaszynska A, Schmitz B, Sugg J, Parikh SJ, List JF. Urinary tract infections in patients with diabetes treated with dapagliflozin. J Diabetes Complications. 2013;27:473-8.

24. Johnsson KM, Ptaszynska A, Schmitz B, Sugg J, Parikh SJ, List JF. Vulvovaginitis and balanitis in patients with diabetes treated with dapagliflozin. J Diabetes Complications. 2013;27:479-84.

25. Henry RR, Murray A, Nauck MA, et al. Response to dapagliflozin by baseline HbA1c in head-to-head comparisons. Diabetes. 2013;62(Suppl 1):A289.

26. Kohan DE, Fioretto P, Tang W, List JF. Long-term study of patients with type 2 diabetes and moderate renal impairment shows that dapagliflozin reduces weight and blood pressure but does not improve glycemic control. Kidney Int. 2014;85:962-71. 